\title{
Experimental and Calculated Electrochemical Potentials of Com- mon Organic Molecules for Applications to Single-Electron Redox Chemistry
}

\author{
Hudson G. Roth \\ Nathan A. Romero \\ David A. Nicewicz*
}

Department of Chemistry, University of North Carolina at Chapel Hill, 125 South Road, Chapel Hill, NC 27599, USA nicewicz@unc.edu

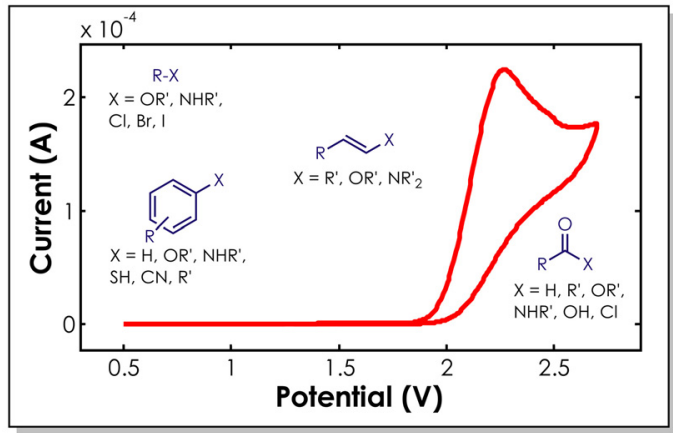

Received: 23.10 .2015

Accepted after revision: 24.11.2015

Published online: 23.12 .2015

DOI: 10.1055/s-0035-1561297; Art ID: st-2015-r0838-c

Abstract Herein, we report half-peak potentials for over 180 organic substrates obtained via cyclic voltammetry. These values are of great use in assessing the thermodynamics of an electron-transfer process. In addition, we disclose a simple computational method to determine redox potentials of organic substrates.

Key words cyclic voltammetry, photoredox catalysis, redox potential, electron transfer, computational chemistry

Over the past few years, photoredox catalysis has opened new avenues for the construction of previously challenging bonds and structural motifs. The rapid development of this area has resulted in the publication of multiple reviews, which we encourage the reader to reference for specific applications. ${ }^{1-3}$ The power of these transformations stems from the cooperation of an oxidant and a reductant that work in tandem to achieve the transformation. Typically, this is enabled by the use of visible light that excites a given catalyst making it capable of undergoing a photoinduced electron-transfer (PET) that would otherwise be endergonic for the ground-state catalyst.

Organic chemists often invoke a simplified means of calculating the Gibbs free energy of a given PET by disregarding coulombic interactions (Equation 1). This requires knowledge of the standard reduction potential for the electron donor $\left(E_{D+/ D}^{0}\right)$ and the acceptor $\left(E_{A / A-}^{0}\right)$, along with $E_{0,0}$ the excited-state energy of the catalyst. However, unlike inorganic species and organometallic complexes, whose redox potentials have been studied extensively, ${ }^{4}$ organic substrates have much less data available for reasons explained below.

$$
\Delta G_{P E T}^{o}=-n \mathcal{F}\left(E_{D^{++} / D}^{o}-E_{A / A^{-}}^{o}-E_{0,0}\right)
$$

Equation 1

Cyclic voltammetry is a common means of measuring the standard reduction potential of a substrate. Since the analyte solution remains unstirred while the potential is scanned, only the molecules at the electrode surface undergo an electron transfer (ET); if this is truly reversible, the oxidized and reduced forms of the substrate will exist in dynamic equilibrium at the electrode surface and the observed current will be directly related to the ET between these two species (Equation 2). A simplified, but reliable, way to calculate $E_{1 / 2}^{0}$ for these system is to average the forward and reverse peak potentials. ${ }^{5}$

$$
E_{1 / 2}^{\mathrm{o}}=-\frac{R T \ln \left(\frac{[\text { [reduced] }}{\text { [oxidized] }]}\right)}{n_{e} \mathcal{F}}=-\frac{\Delta G_{1 / 2}^{\mathrm{o}}}{n_{e} \mathcal{F}}
$$

Equation 2

The lack of data on organic substrates stems in part from the fact that they often exhibit irreversible cyclic voltammograms ( $\mathrm{CV}$, Figure 1 ). This is due to the reactivity of the oxidized/reduced species which leads to rapid degradation (Scheme 1). ${ }^{6}$ Therefore, the redox couple is not in equilibrium at the electrode surface and the current observed is related to the rate of electron transfer, which complicates the calculation of $E_{1 / 2}^{0}$ as the ET rate constant is required. ${ }^{6} \mathrm{~A}$ number of corrections for determining the true $E_{1 / 2}^{0}$ value have been developed, but these require knowledge of the competing pathway(s) and the corresponding rate constant(s). An example of this has been published by Savéant for thiophenoxides. ${ }^{7}$ Even though this gives a more accurate 

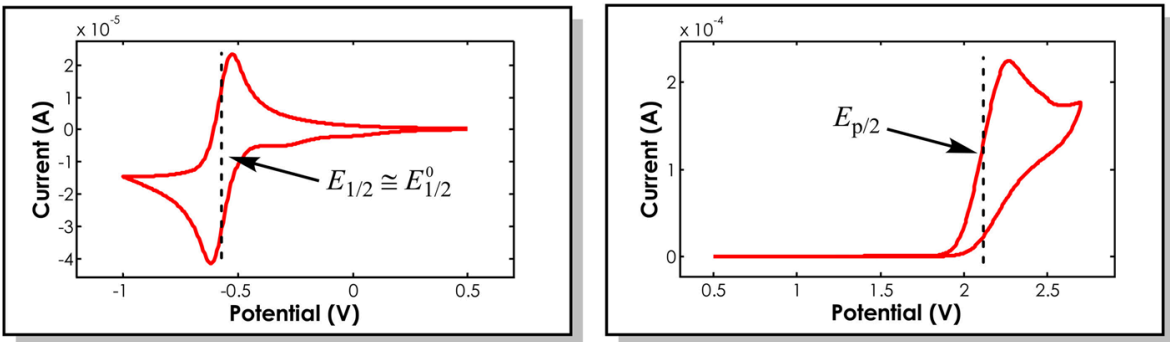

Figure 1 Representative CV demonstrating reversible (left) and irreversible (right) electron transfers.
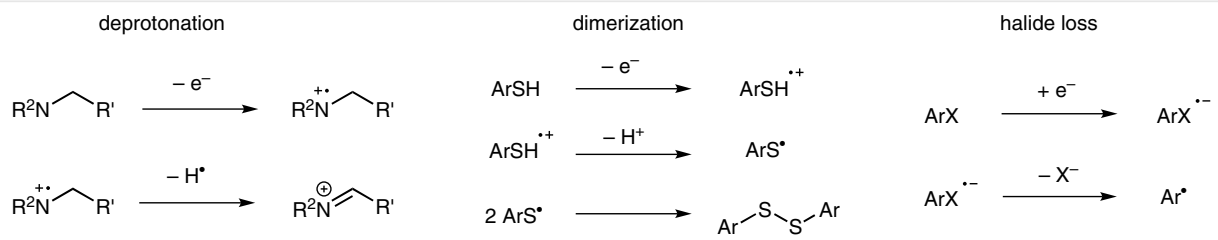

Scheme 1 Common degradation pathways for organic substrates that prevent back electron transfer in CV experiments

understanding of the thermodynamics for a given ET, the experimental set-up and time required to collect the data can make it difficult to obtain.

One approach to estimating $E_{1 / 2}^{0}$ for a compound is to utilize the peak potential $\left(E_{\mathrm{p}}\right){ }^{4}$ However, we found that peak potentials consistently overestimated the redox potentials for compounds whose thermodynamics potentials have been accurately measured by nonelectrochemical techniques that are impervious to corruption by fast decomposition. 8 ,9 For example, we find a peak potential of $2.3 \mathrm{~V}$ vs. SCE for mesitylene (see Supporting Information, Figure $\mathrm{S} 1$ ), whereas the accurate $E^{0}{ }_{1 / 2}$ value reported by Farid et al. is $2.05 \pm 0.01 \mathrm{~V}$ vs. SCE.

Alternatively, one can use half-peak potentials $\left(E_{\mathrm{p} / 2}\right)$, which correspond to the potential at half the maximum current in the $C V$, as a way to estimate $E_{1 / 2}^{0}{ }^{10}$ For mesity-

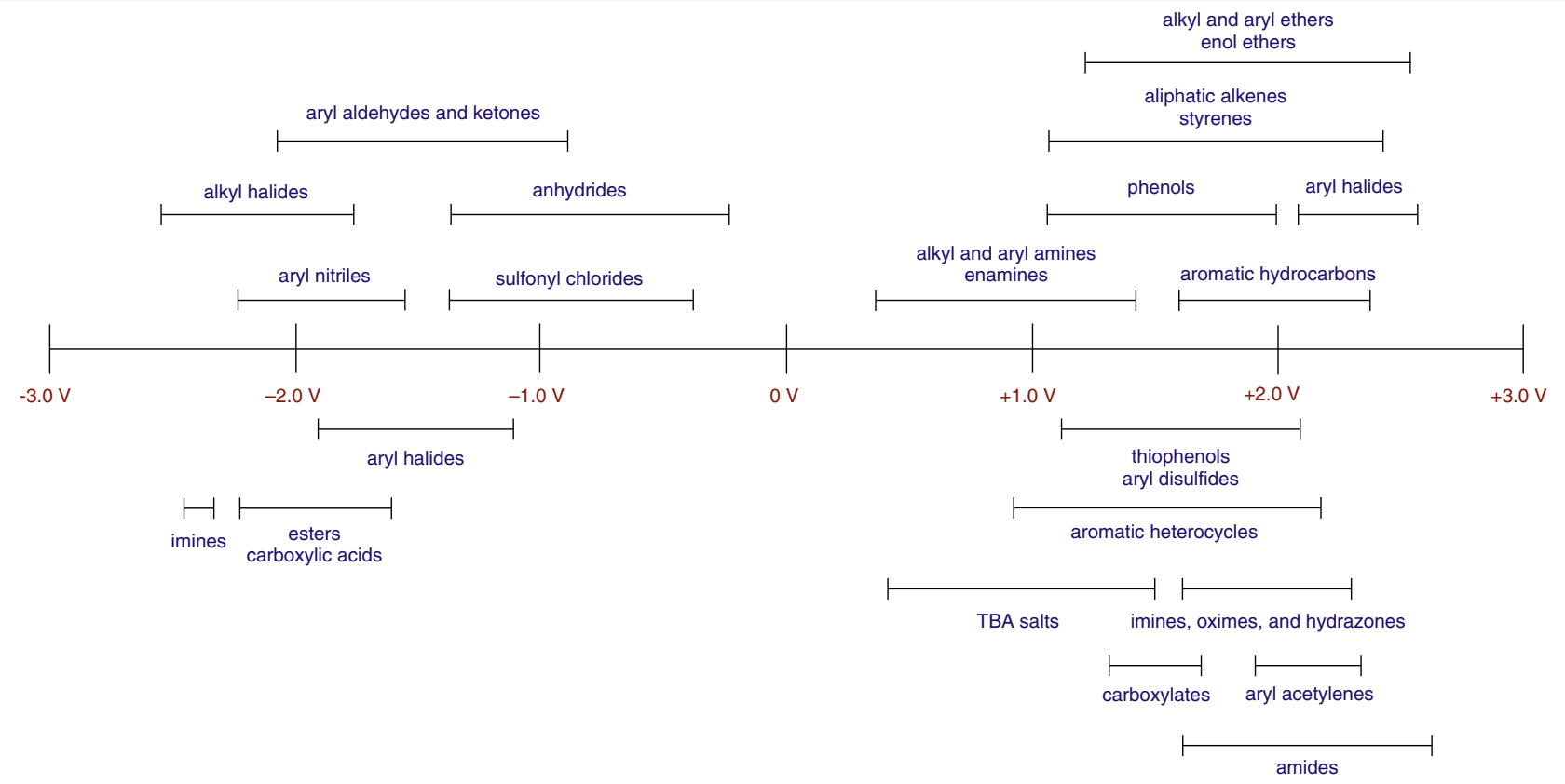

Figure 2 Electrochemical series of common organic functional groups; potentials are reported against SCE 


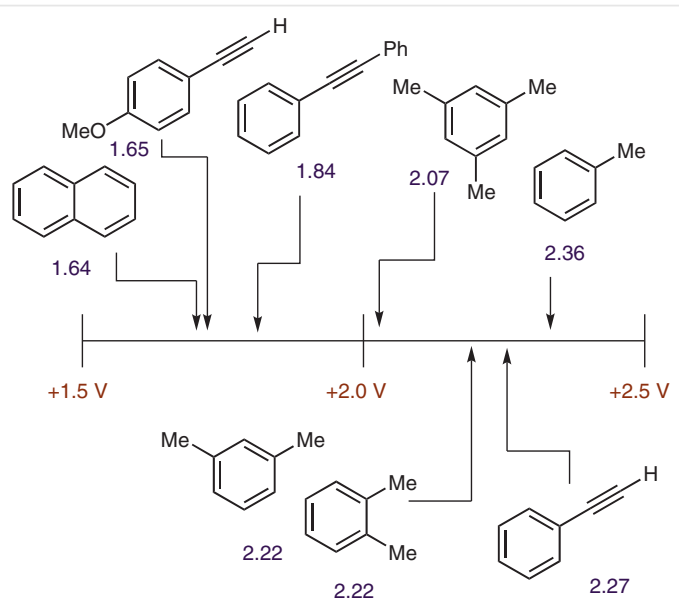

Figure 3 Electrochemical series of aromatic hydrocarbons and aryl alkynes; potentials are reported against SCE

lene, we measure an $E_{\mathrm{p} / 2}$ of $2.07 \mathrm{~V}$ vs. SCE, which is in satisfactory range of the potential reported by Farid. Moreover, half-peak potentials have been previously utilized as a preferred approach to estimating $E_{1 / 2}^{0} \cdot{ }^{11}$ Since these values are easily obtained with a basic electrochemical setup, we advocate they are sufficient for the purposes of the organic chemist since they still provide an assessment of the $\Delta G^{0}$ for a given PET.
However, we want to emphasize that since these values are not truly reflective of $E_{1 / 2}^{0}$, the value of $\Delta G$ calculated should not be taken as absolute due to the issues explained above. For strict determination of the true $E_{1 / 2}^{0}$ value for a given substrate, we direct the reader to studies addressing this topic. ${ }^{12-14}$

In an effort to make $E_{\mathrm{p} / 2}$ values more available and utilized by synthetic chemists, primarily for the application of photoredox catalysis, we report the redox potentials of over 180 organic substrates. Analytes are organized by functional groups and potentials are reported in volts against the saturated calomel electrode (SCE, Figure 2). As they are reported here, negative values indicate reductions while positive ones signify oxidations.

Furthermore, we conducted all experiments with a standard set of conditions to maintain internal consistency; this included performing all measurements with the same scan rate as this is known to have a subtle impact on $E_{\mathrm{p} / 2}$ values. ${ }^{15}$ In addition, to reduce the ambiguity of the reported potentials, we follow the suggestions by Addison and provide 1) an experimental $E_{1 / 2}^{0}$ value for a standard redox couple, namely $\mathrm{Fc}^{+} / \mathrm{Fc}^{16}$ and 2 ) the means by which we converted measured values from silver-silver chloride into SCE. ${ }^{17,18}$

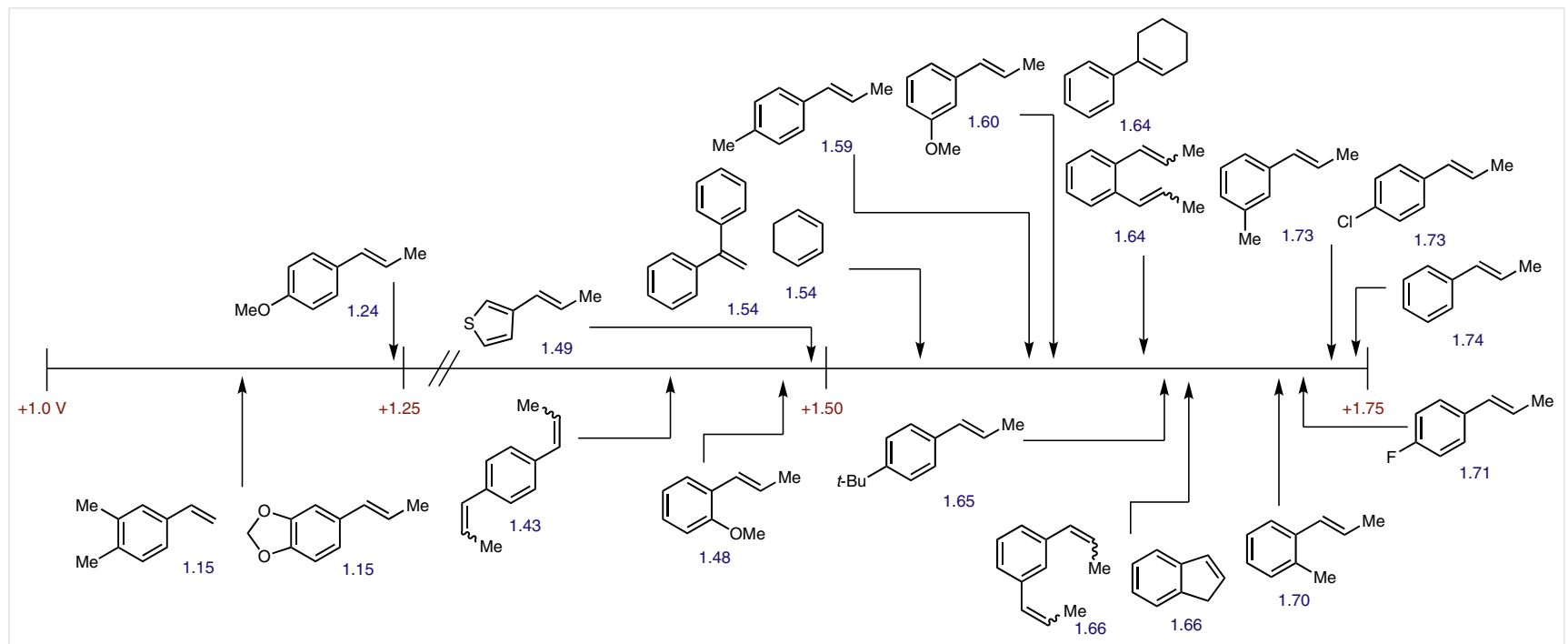

Figure 4 Electrochemical series of alkenes $(+1.0$ to $+1.75 \mathrm{~V})$; potentials are reported against SCE 


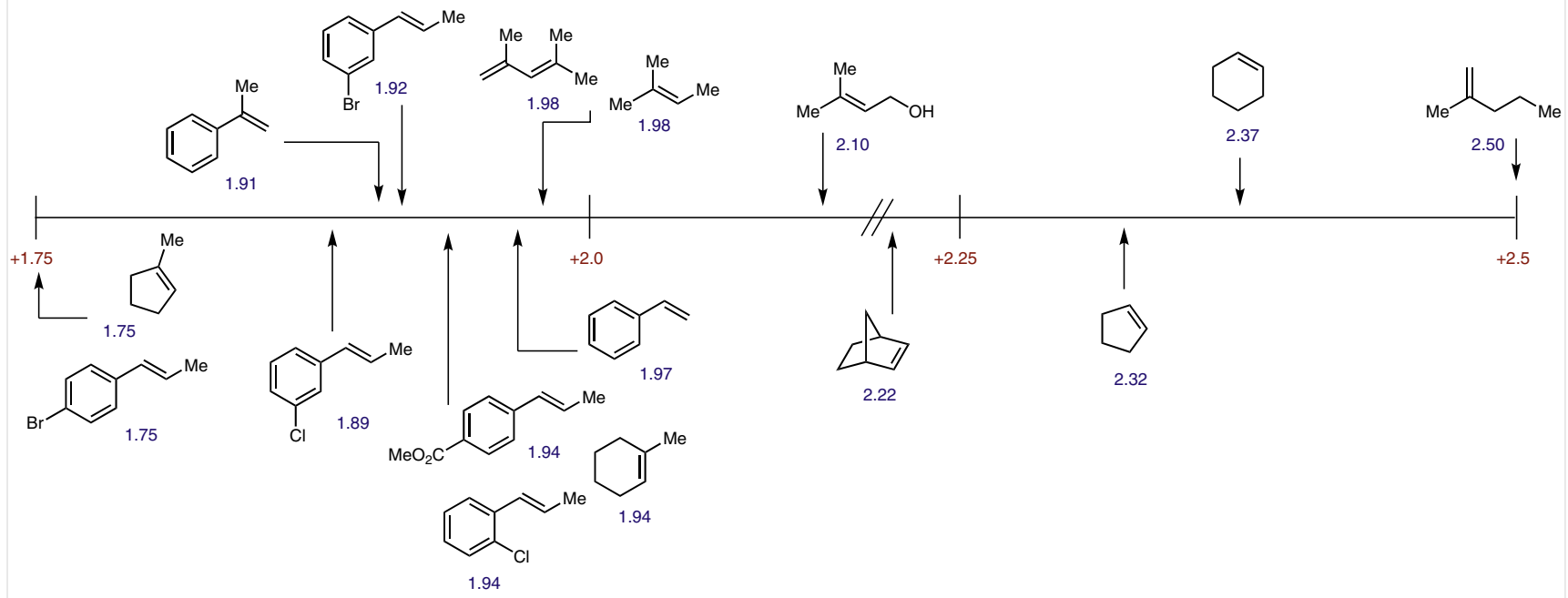

Figure 5 Electrochemical series of alkenes $(+1.75$ to $+2.5 \mathrm{~V})$; potentials are reported against SCE

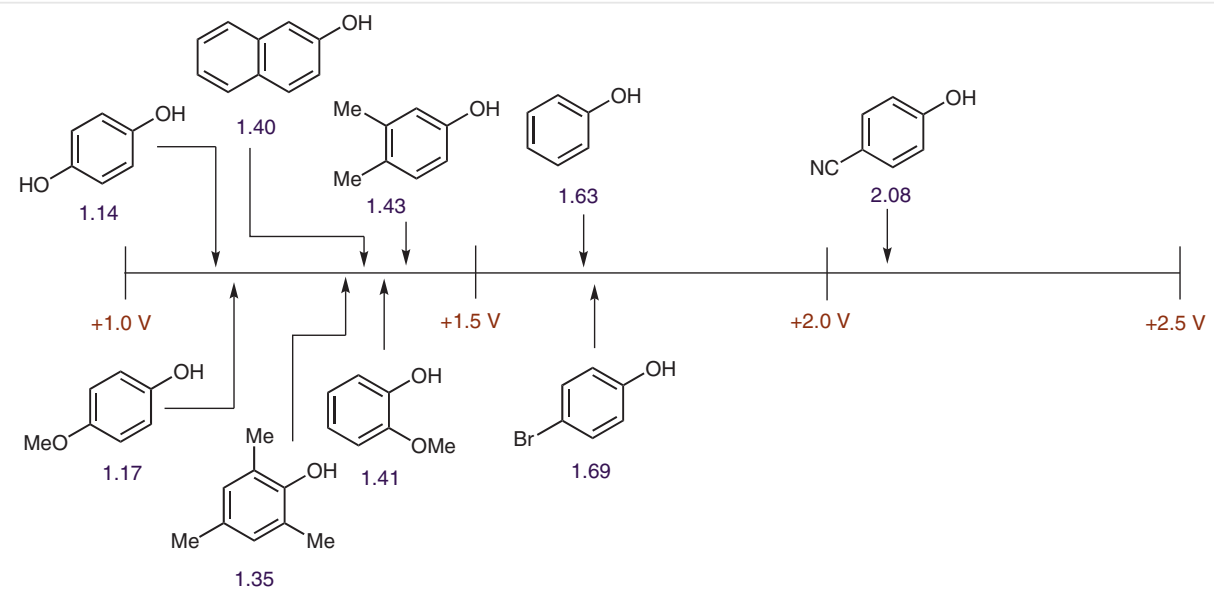

Figure 6 Electrochemical series of phenols; potentials are reported against SCE

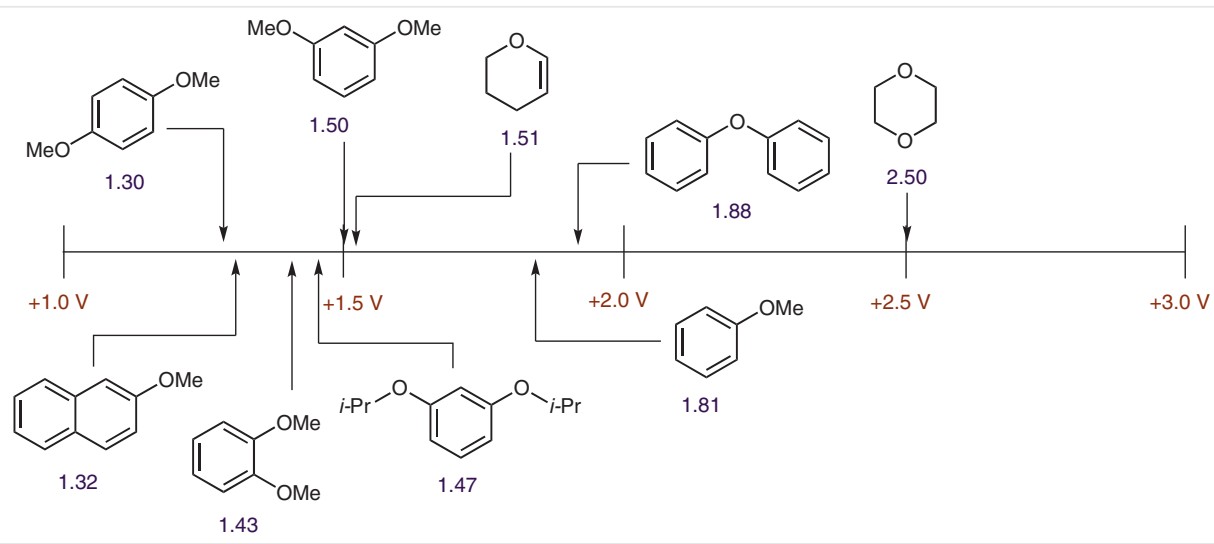

Figure 7 Electrochemical series of ethers; potentials are reported against SCE 


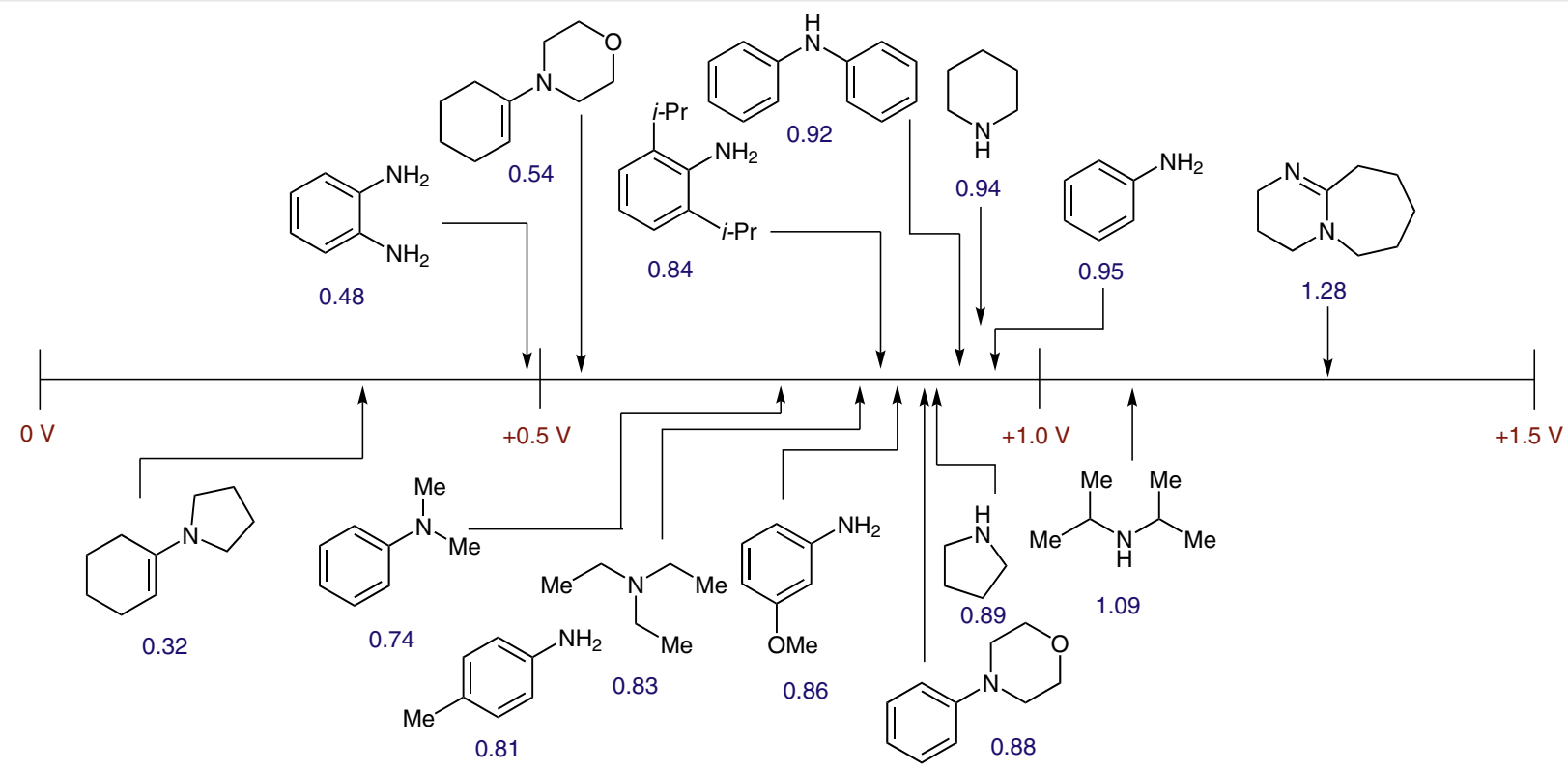

Figure 8 Electrochemical series of amines; potentials are reported against SCE

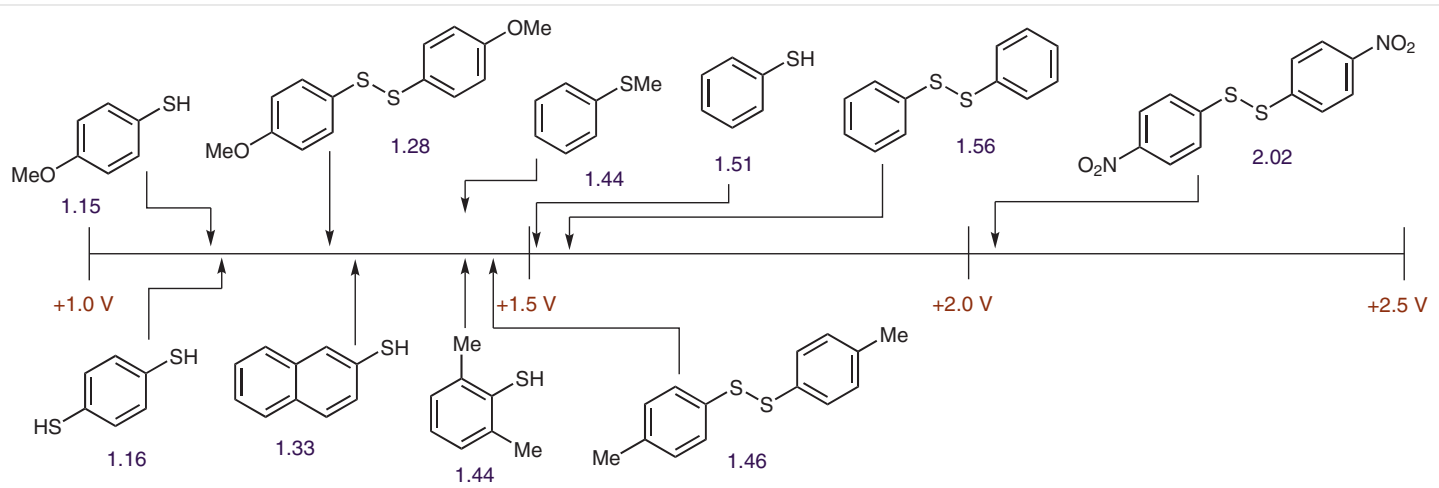

Figure 9 Electrochemical series of thiophenols and aryl disulfides; potentials are reported against SCE

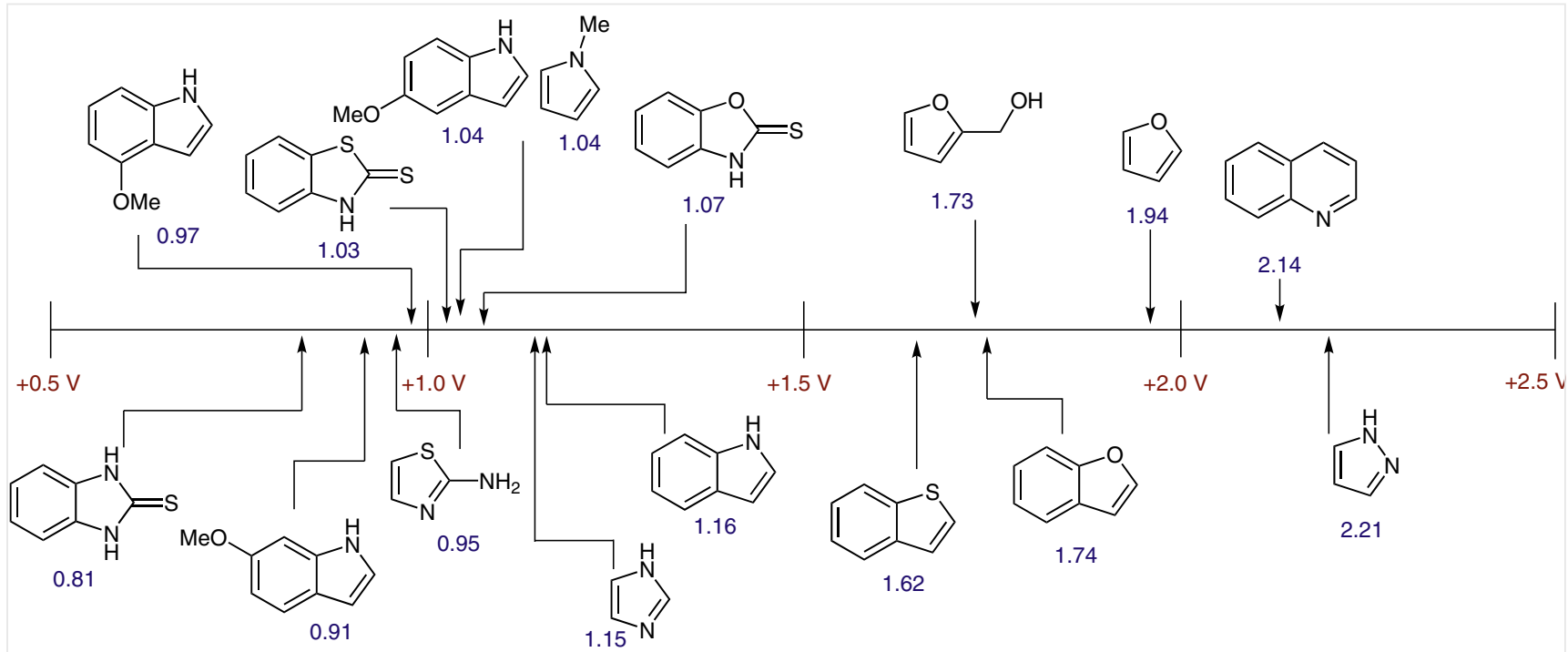

Figure 10 Electrochemical series of aromatic heterocycles; potentials are reported against SCE 


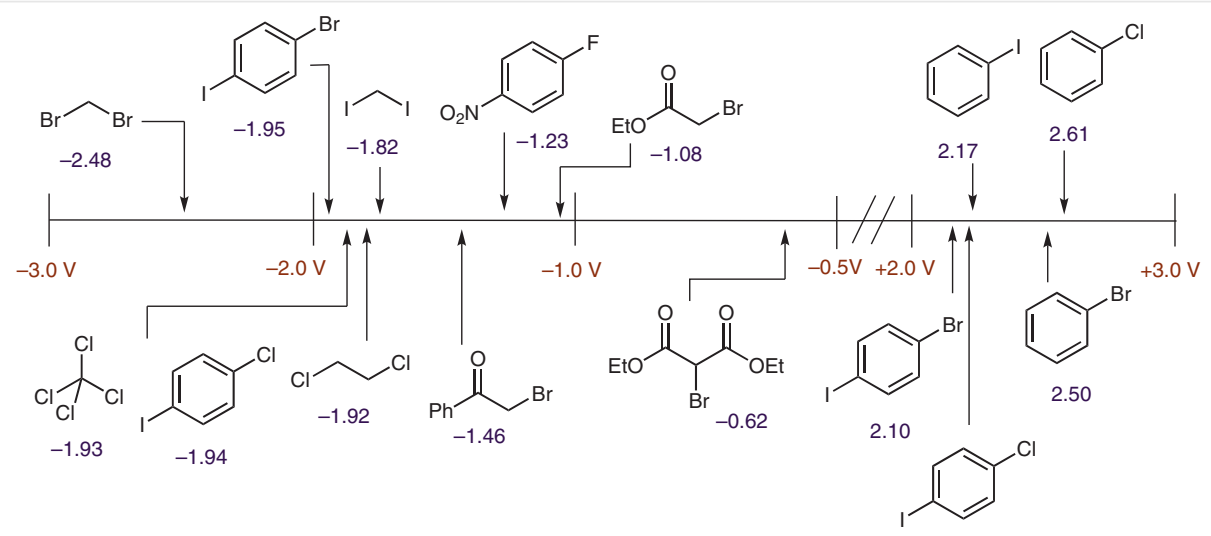

Figure 11 Electrochemical series of alkyl and aryl halides; potentials are reported against SCE

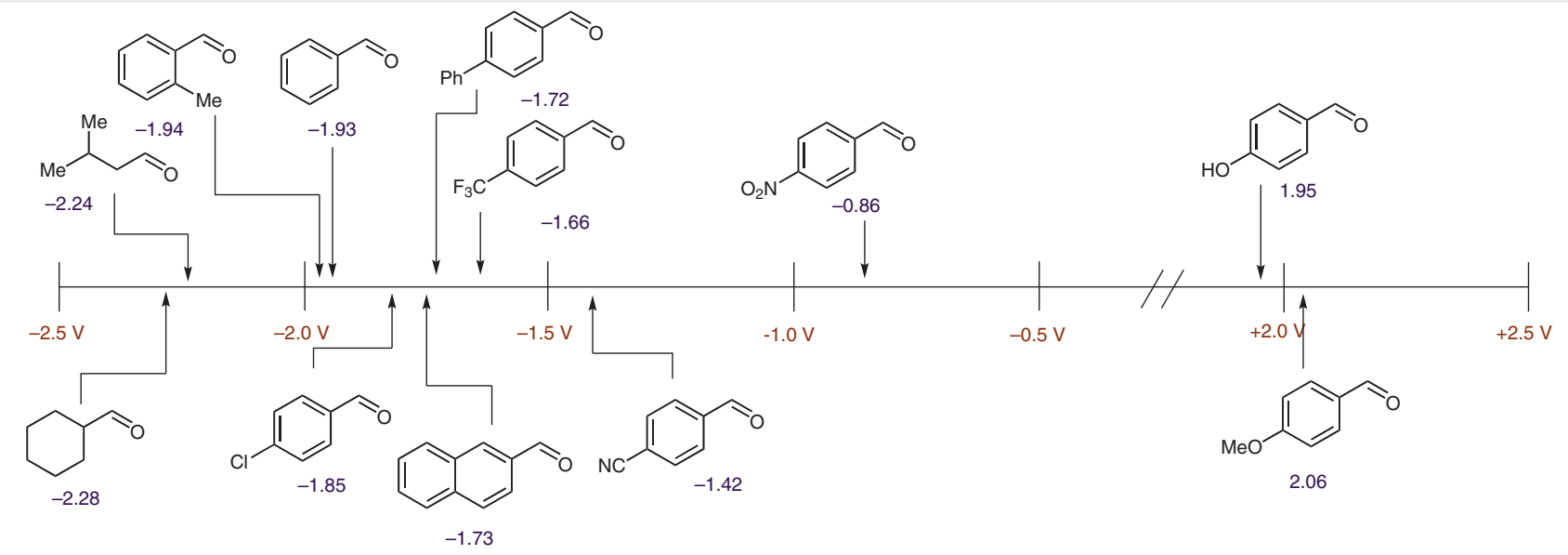

Figure 12 Electrochemical series of aldehydes; potentials are reported against SCE

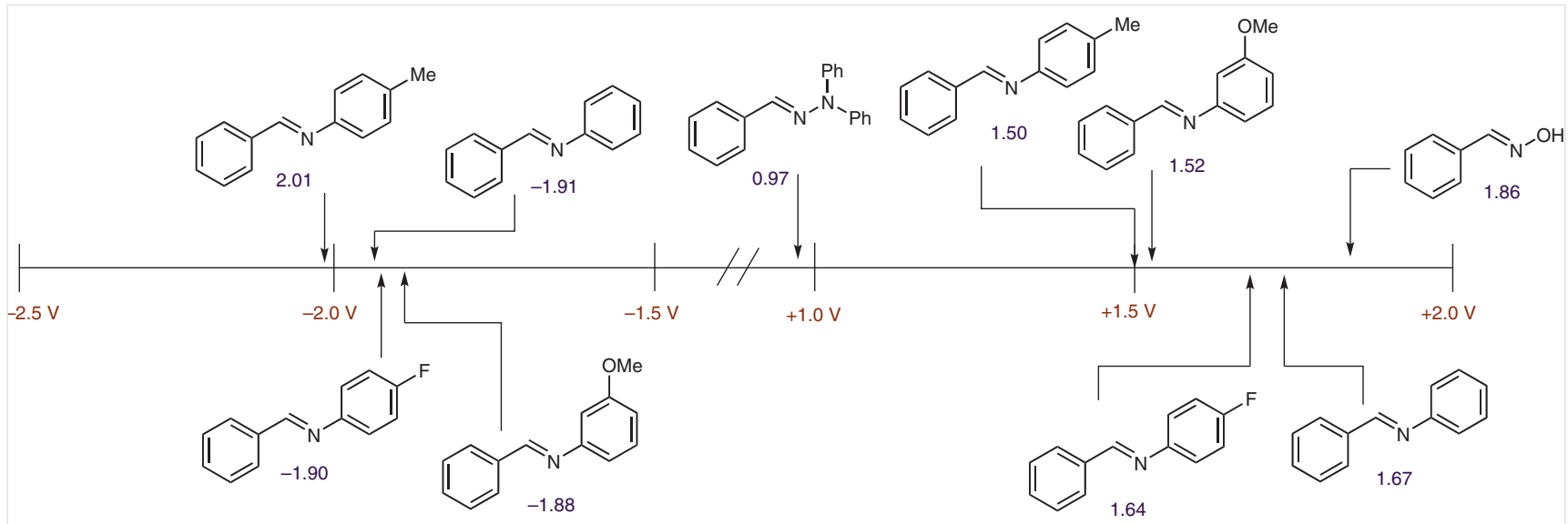

Figure 13 Electrochemical series of benzaldehyde-derived imines; potentials are reported against SCE 


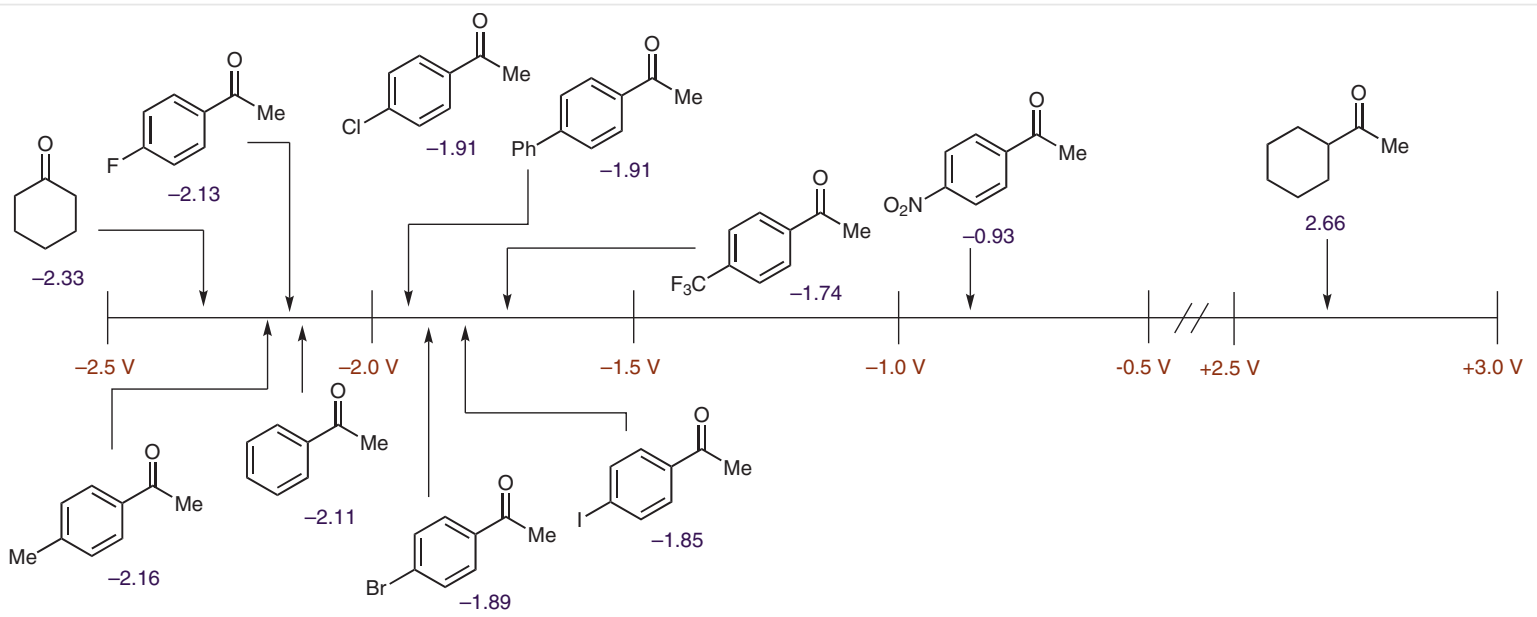

Figure 14 Electrochemical series of ketones; potentials are reported against SCE

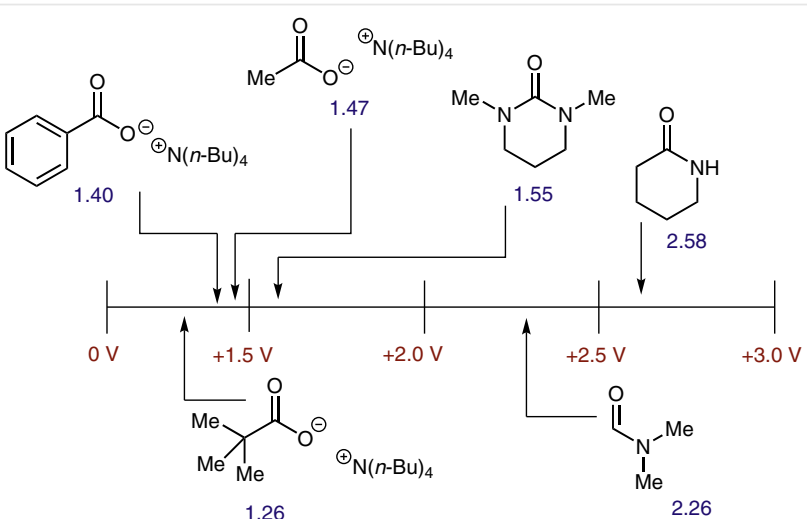

Figure 15 Electrochemical series of amides and TBA carboxylates; potentials are reported against SCE

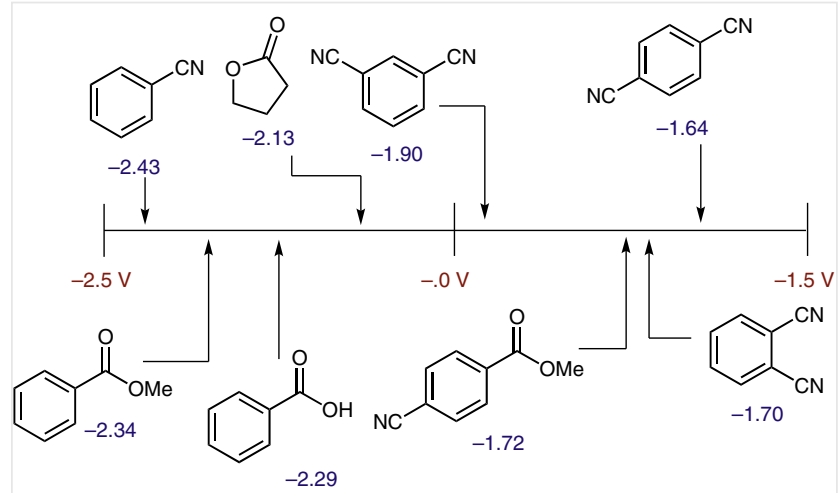

Figure 16 Electrochemical series of carboxylic acids, esters, and nitriles; potentials are reported against SCE

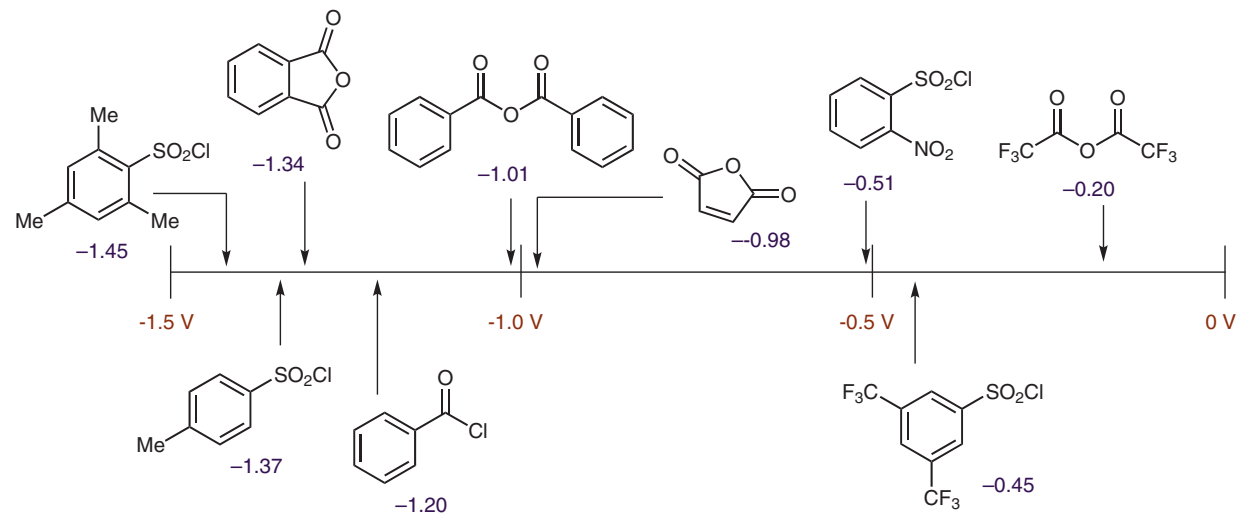

Figure 17 Electrochemical series of acyl/sulfonyl chlorides and anhydrides; potentials are reported against SCE 


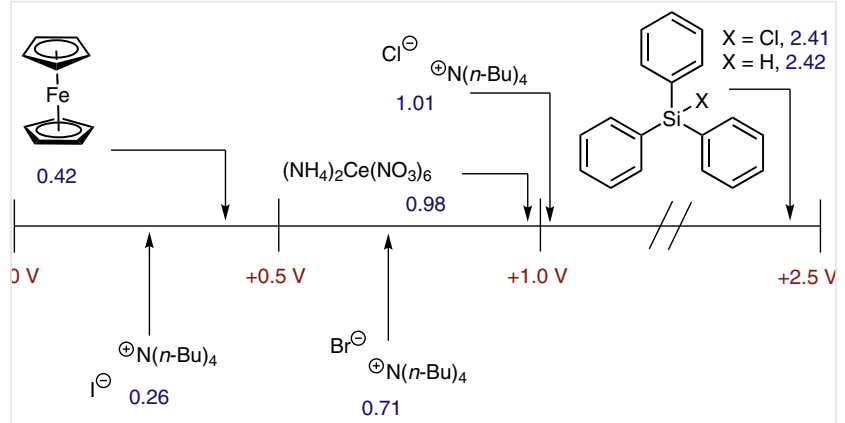

Figure 18 Electrochemical series of inorganics, arylsilanes, and TBA halides; potentials are reported against SCE

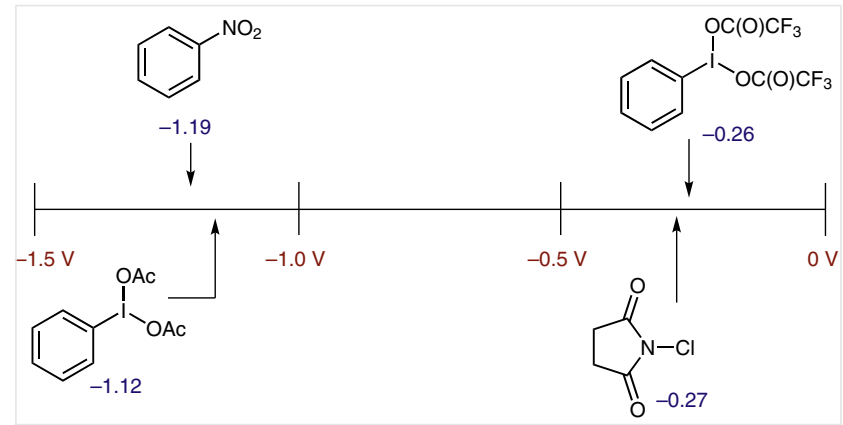

Figure 19 Electrochemical series of hypervalent iodines, nitrobenzene, and $\mathrm{N}$-chlorosuccinimide; potentials are reported against SCE

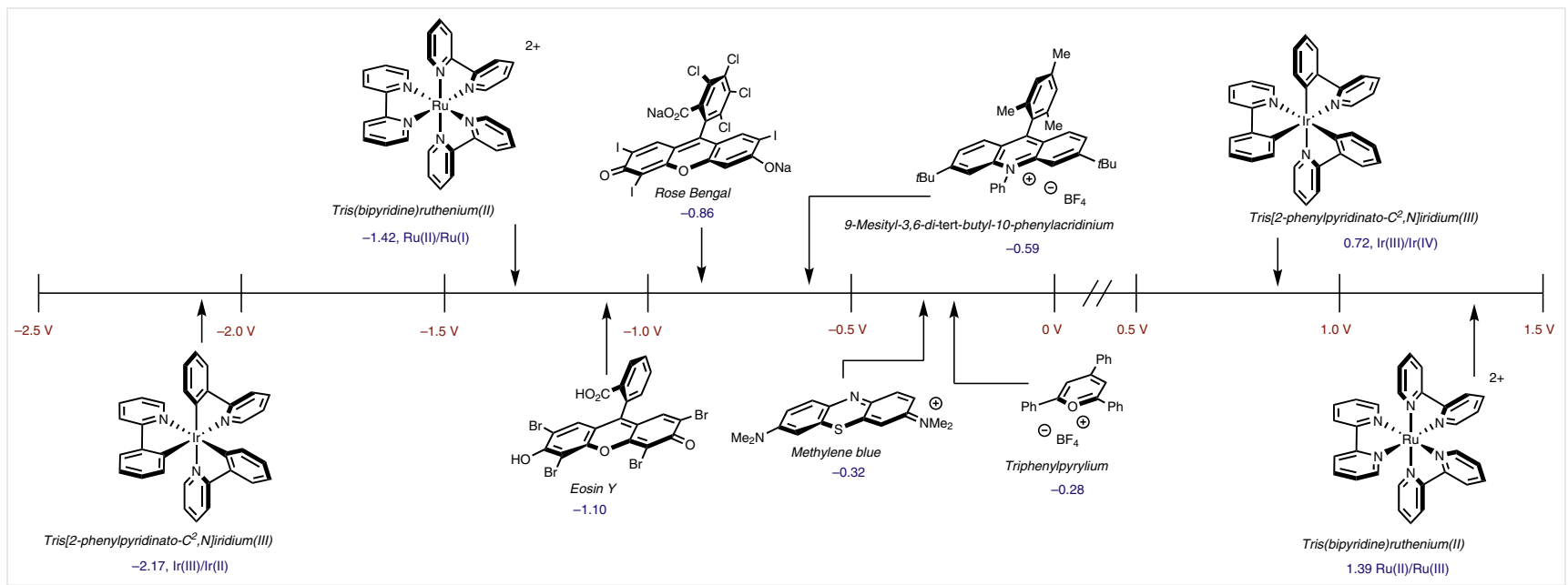

Figure 20 Electrochemical series of photoredox catalysts; potentials are reported against SCE

Oxidation potentials were obtained for aromatic hydrocarbons and aryl acetylenes (Figure 3), aliphatic and aromatic olefins (Figure 4 and Figure 5). For simple aliphatic alkynes, no peak was observed within the electrochemical potential window of acetonitrile. Arenes bearing oxygen (Figure 6 and Figure 7), nitrogen (Figure 8), or sulfur-based (Figure 9) substituents were also measured. Oxidation potentials decrease according to $\mathrm{O}>\mathrm{S}>\mathrm{N}$. Aliphatic and alkenyl groups bearing oxygen/nitrogen are also reported. Oxidation potentials for a representative sample of heterocycles bearing $\mathrm{O}, \mathrm{N}$, and S were measured (Figure 10). Simple aliphatic and aromatic halides were investigated; the ease of oxidation and reduction follows $\mathrm{I}>\mathrm{Br}>\mathrm{Cl}$ (Figure 11). Redox data on aldehydes (Figure 12) and benzaldehyde-derived imines, oximes, and hydrazones (Figure 13) were also gathered. A variety of substituted acetophenones and alkyl ketones were also investigated (Figure 14). Oxidation potentials for amides and tetra- $n$-butylammonium carboxylate salts (Figure 15) were collected along with reduction potentials of carboxylic acids, esters, and nitriles (Figure 16), plus acyl/sulfonyl chlorides and anhydrides (Figure 17). Electrochemical potentials of ferrocene, ceric ammonium nitrate, tetra- $n$-butylammonium halides, and aryl silanes were collected (Figure 18) along with reduction potentials of nitroarenes, hypervalent iodides, and succinimides (Figure 19). Ground-state potentials were obtained for a variety of catalysts commonly employed in photoredox-mediated transformations (Figure 20). As these species are quite well studied, information on their corresponding excited-state potentials can be readily found in the literature along with examples of their applications. ${ }^{1-3}$

The complications associated with measuring accurate electrochemical potentials of organic molecules - particularly when irreversible couples are involved - has prompted the application of computational methods to electrochemical inquiries. ${ }^{19-24}$ Previous attempts to correlate redox potentials calculated by DFT with experimental data mostly rely on redox potentials gathered from multiple sources in the literature. ${ }^{20,24}$ Although these studies generally find at least moderate correspondence between calculation and experiment, comparison with a single source of electrochemical data would eliminate the difficulty in completely accounting for experimental differences (such as working electrode, reference electrode, and scan rate) when concatenating data from various sources. This motivated us to carry out DFT calculations on the data set presented herein. 
The general procedure for theoretical prediction of redox potentials primarily involves calculation of the free energy difference $\left(\Delta \mathrm{G}^{0, \text { calc }}{ }_{1 / 2}\right.$, Equation 3$)$ between reduced and oxidized forms, which is, in turn, related to $\mathrm{E}^{0, \text { calc }_{1 / 2}}$ by Equation 4 by referencing to an absolute potential for a standard electrode. ${ }^{25}$ Most studies to date have followed a free energy cycle to translate gas-phase to solution-phase energies, ${ }^{19,24}$ requiring separate calculation of the solvation energy associated with each species (i.e., reduced and oxidized). A related and operationally simpler approach is to calculate the free energies under a solvation model, thus calling for only two distinct steps which require significant computation. ${ }^{19}$ By either approach, implicit solvation models can be employed successfully, although the most accurate results have been obtained when 'custom' solvation parameters are determined by separate optimization. ${ }^{24} \mathrm{We}$ were interested in evaluating a relatively simple computational procedure, with the hope that a more accessible method would be most widely useful.

$$
\Delta G_{1 / 2}^{\text {o,calc }}=G_{298}(\text { reduced })-G_{298}(\text { oxidized })
$$

Equation 3

$$
E_{1 / 2}^{\text {o,calc }}=-\frac{\Delta G_{1 / 2}^{\text {o,calc }}}{n_{e} \mathcal{F}}-E_{1 / 2}^{\text {orref }}
$$

Equation 4

With this in mind, we calculated the redox potentials for this data set with the frequently used B3LYP 26,27 and M06-2X ${ }^{28}$ functionals, the split valence basis set $6-31+G(d, p),{ }^{29,30}$ and the CPCM solvent continuum approach to account for solvation in $\mathrm{MeCN} .^{31,32}$ All calculations were carried out in Gaussian 09,33 and structures were submitted to geometry optimization, with frequency calculations performed on the optimized structures both to verify that the geometries were true minima and to calculate free energies at $298 \mathrm{~K}$. The solution-phase energies were referenced to SCE by subtraction of $4.281 \mathrm{~V}$ (abs. potential of SHE) ${ }^{25}$ and $0.141 \mathrm{~V}$ (conversion of SHE into SCE in $\mathrm{MeCN}){ }^{25}$ In some cases, minimized geometries could not be reached, owing to fragmentation of the one-electron oxidized or reduced species (a pathway particularly relevant in alkyl and aryl halides), and no further analysis was carried out for these molecules. The potentials successfully computed with both functionals were compared with the experimental electrochemical potentials, and the results are shown in Figure 21. Both methodologies give a reasonable correlation with the experimental potentials, each exhibiting comparable variation [standard deviation of $\left(E_{\text {calc }}-E_{\text {exp }}\right)$ for B3LYP $=0.30$ and for M06-2X = 0.29; see Supporting Information, Figures S51-S52]. Ultimately, B3LYP/6$31+G(d, p)$ offers better overall performance, seen as a near overlay of the regression with the black line representing an ideal agreement between theory and experiment. Whereas B3LYP slightly overestimates reduction potentials and slightly underestimates oxidation potentials, M06-2X overestimates oxidation potentials more significantly (Supporting Information, Figure S52), which largely contributes to the global deviation seen for M06-2X. Consideration of individual plots corresponding to the electrochemical series presented in Figures 13-19 (Supporting Information, Figures S35-S50) provides a measure of the strengths and weaknesses of this general analysis. Specifically, some electrochemical series reveal discrepancies between the calculated and experimental potentials for certain molecules. Conspicuously, DFT calculations overestimate the oxidation potentials for $\mathrm{I}^{-}, \mathrm{Br}^{-}$, and $\mathrm{Cl}^{-}$, by approximately $100 \%$ for each halide, and this may signal inadequate treatment of solvation, as previous studies found that use of doubly diffuse basis sets led to improved accuracy in anionic species. ${ }^{20,34}$ Other notable deviations in calculated oxidation potentials are observed in the case of several aromatic heterocycles, such as imidazole and the series of thioamides, benzoxazole-2-thione, benzothiazole-2-thione, and benzoimidazole-2-thione (Figures 10 and S41), for which the potentials are overestimated by about $0.5-1.2 \mathrm{~V}$. Although we investigated the 2-mercapto (thiol) form of the benzoazoles, which showed no significant improvement, one study has suggested that the equilibrium between $\mathrm{C}=\mathrm{S}$ and $\mathrm{C}-\mathrm{SH}$ forms shifts towards the $\mathrm{C}-\mathrm{SH}$ tautomer as the oxidation proceeds. ${ }^{35}$ This is likely to complicate the computational analysis.

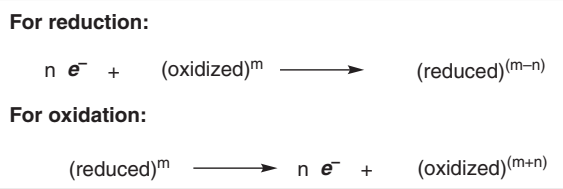

Scheme 2 Half reactions for reduction and oxidation

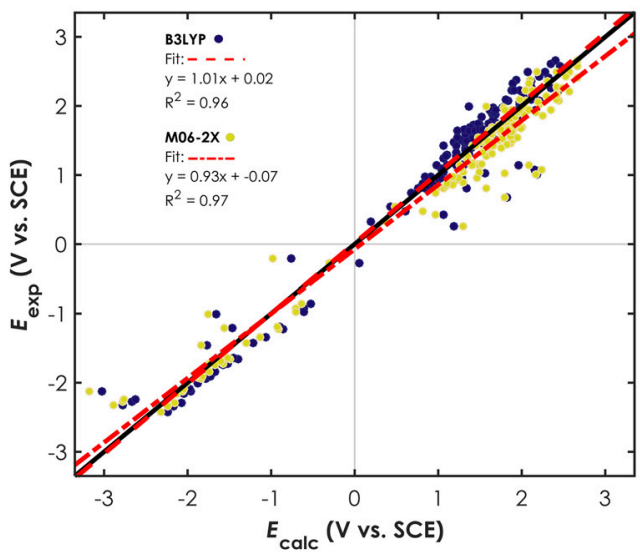

Figure 21 Plot of experimental vs. calculated redox potentials for a series of organic compounds 
Despite the well-documented pitfalls of DFT in describing the electronic structure of anion radicals, ${ }^{36-39}$ we find that the calculated reduction potentials give a reasonable correlation with the experiment. The most noticeable deviations occur in the overestimation of the reduction potentials for trifluoracetic anhydride (Figures 17 and S46) and $\gamma$-butyrolactone (Figures 15 and S45). Notably, the radical anions of these two structures exhibit pyramidalization of a $\mathrm{C}=\mathrm{O}$ unit, in contrast to the other esters and anhydrides studied which possess extended $\pi$ systems adjacent to the carbonyl available for delocalization of the added electron density. We speculate that the observed anomalies may be manifestations of DFT's difficulty in describing systems where symmetry or delocalization changes upon ionization. ${ }^{40,41}$

Overall, the results of these computational studies reveal a reasonable correlation between experimental and theoretical electrochemical redox potentials when using a relatively simple and computationally efficient approach. While B3LYP appears to be the more accurate level of theory, both functionals give rise to deviations in selected cases. Nonetheless, we believe this study validates DFT as a useful tool in predicting solution-phase redox potentials.

\section{Acknowledgment}

This research was supported by an NSF-CAREER grant (CHE1352490). N.A.R. is also grateful for an NSF Graduate Fellowship.

\section{Supporting Information}

Supporting information for this article is available online at http://dx.doi.org/10.1055/s-0035-1561297.

\section{References and Notes}

(1) Xi, Y.; Yi, H.; Lei, A. Org. Biomol. Chem. 2013, 11, 2387.

(2) Prier, C. K.; Rankic, D. A.; MacMillan, D. W. C. Chem. Rev. 2013, $113,5322$.

(3) Nguyen, T. M.; Nicewicz, D. A. J. Am. Chem. Soc. 2013, 135, 9588.

(4) Connelly, N. G.; Geiger, W. E. Chem. Rev. 1996, 96, 877.

(5) Mabbott, G. A. J. Chem. Educ. 1983, 60, 697.

(6) Brownson, D. A. C.; Banks, C. E. The Handbook of Graphene Electrochemistry; Springer: London, 2014.

(7) Andrieux, C. P.; Hapiot, P.; Pinson, J.; Saveant, J. M. J. Am. Chem. Soc. 1993, 115, 7783.

(8) Merkel, P. B.; Luo, P.; Dinnocenzo, J. P.; Farid, S. J. Org. Chem. 2009, 74, 5163.

(9) Luo, P.; Feinberg, A. M.; Guirado, G.; Farid, S.; Dinnocenzo, J. P. J. Org. Chem. 2014, 79, 9297.

(10) IUPAC Compendium of Chemical Terminology; Nič, M.; Jirát, J.; Košata, B.; Jenkins, A.; McNaught, A., Eds.; IUPAC: Oxford, 2009.

(11) Xu, H.-C.; Moeller, K. D. Angew. Chem. Int. Ed. 2010, 49, 8004.

(12) Andrieux, C. P.; Blocman, C.; Dumas-Bouchiat, J. M.; Saveant, J. M. J. Am. Chem. Soc. 1979, 101, 3431.
(13) Andrieux, C. P.; Gallardo, I.; Saveant, J. M. J. Am. Chem. Soc. 1989, $111,1620$.

(14) Klingler, R. J.; Kochi, J. K. J. Phys. Chem. 1981, 85, 1731.

(15) See Supporting Information for details.

(16) Measuring the $\mathrm{Fc}^{+} / \mathrm{Fc}$ redox couple using our experimental conditions afforded $E_{1 / 2}=+0.45 \mathrm{~V}$ vs. $\mathrm{Ag} \mid \mathrm{AgCl}$. Conversion to voltages vs SCE involved the subtraction of $0.03 \mathrm{~V}$ for this and all other measurements, providing a value of $+0.42 \mathrm{~V}$ for the $\mathrm{Fc}^{+} / \mathrm{Fc}$ couple.

(17) Pavlishchuk, V. V.; Addison, A. W. Inorg. Chim. Acta 2000, 298, 97.

(18) Thomas, K. R. J.; Tharmaraj, P.; Chandrasekhar, V.; Bryan, C. D.; Cordes, A. W. Inorg. Chem. 1994, 33, 5382.

(19) Keith, J. A.; Carter, E. A. J. Am. Chem. Soc. 2012, 134, 7580.

(20) Baik, M.-H.; Friesner, R. A. J. Phys. Chem. A 2002, 106, 7407.

(21) Winget, P.; Weber, E. J.; Cramer, C. J.; Truhlar, D. G. Phys. Chem. Chem. Phys. 2000, 2, 1231.

(22) Uudsemaa, M.; Tamm, T. J. Phys. Chem. A 2003, 107, 9997.

(23) Baik, M.-H.; Silverman, J. S.; Yang, I. V.; Ropp, P. A.; Szalai, V. A.; Yang, W.; Thorp, H. H. J. Phys. Chem. B 2001, 105, 6437.

(24) Fu, Y.; Liu, L.; Yu, H.-Z.; Wang, Y.-M.; Guo, Q.-X. J. Am. Chem. Soc. 2005, 127, 7227.

(25) Isse, A. A.; Gennaro, A. J. Phys. Chem. B 2010, 114, 7894.

(26) Lee, C.; Yang, W.; Parr, R. G. Phys. Rev. B: Condens. Matter Mater. Phys. 1988, 37, 785.

(27) Becke, A. D. J. Chem. Phys. 1993, 98, 5648.

(28) Zhao, Y.; Truhlar, D. G. Theor. Chem. Acc. 2007, 120, 215.

(29) Krishnan, R.; Binkley, J. S.; Seeger, R.; Pople, J. A. J. Chem. Phys. 1980, 72, 650 .

(30) McLean, A. D.; Chandler, G. S. J. Chem. Phys. 1980, 72, 5639.

(31) Barone, V.; Cossi, M. J. Phys. Chem. A 1998, 102, 1995.

(32) Cossi, M.; Rega, N.; Scalmani, G.; Barone, V. J. Comput. Chem. 2003, 24, 669 .

(33) Frisch, M. J.; Trucks, G. W.; Schlegel, H. B.; Scuseria, G. E.; Robb, M. A.; Cheeseman, J. R.; Scalmani, G.; Barone, V.; Mennucci, B.; Petersson, G. A.; Nakatsuji, H.; Caricato, M.; Li, X.; Hratchian, H. P.; Izmaylov, A. F.; Bloino, J.; Zheng, G.; Sonnenberg, J. L.; Hada, M.; Ehara, M.; Toyota, K.; Fukuda, R.; Hasegawa, J.; Ishida, M.; Nakajima, T.; Honda, Y.; Kitao, O.; Nakai, H.; Vreven, T.; Montgomery, J. A. Jr.; Peralta, J. E.; Ogliaro, F.; Bearpark, M.; Heyd, J. J.; Brothers, E.; Kudin, K. N.; Staroverov, V. N.; Kobayashi, R.; Normand, J.; Raghavachari, K.; Rendell, A.; Burant, J. C.; Iyengar, S. S.; Tomasi, J.; Cossi, M.; Rega, N.; Millam, J. M.; Klene, M.; Knox, J. E.; Cross, J. B.; Bakken, V.; Adamo, C.; Jaramillo, J.; Gomperts, R.; Stratmann, R. E.; Yazyev, O.; Austin, A. J.; Cammi, R.; Pomelli, C.; Ochterski, J. W.; Martin, R. L.; Morokuma, K.; Zakrzewski, V. G.; Voth, G. A.; Salvador, P.; Dannenberg, J. J.; Dapprich, S.; Daniels, A. D.; Farkas, Ö.; Foresman, J. B.; Ortiz, J. V.; Cioslowski, J.; Fox, D. J. Gaussian 09, Revision D.01; Gaussian Inc: Wallingford, 2009.

(34) Galbraith, J. M.; Iii, H. F. S. J. Chem. Phys. 1996, 105, 862.

(35) Kouroulis, K. N.; Hadjikakou, S. K.; Kourkoumelis, N.; Kubicki, M.; Male, L.; Hursthouse, M.; Skoulika, S.; Metsios, A. K.; Tyurin, V. Y.; Dolganov, A. V.; Milaeva, E. R.; Hadjiliadis, N. Dalton Trans. 2009, 10446.

(36) Lee, D.; Furche, F.; Burke, K. J. Phys. Chem. Lett. 2010, 1, 2124.

(37) Patterson, E. V.; Cramer, C. J.; Truhlar, D. G. J. Am. Chem. Soc. 2001, 123, 2025.

(38) Kim, M.-C.; Sim, E.; Burke, K. Phys. Rev. Lett. 2013, 111, 073003.

(39) Rösch, N.; Trickey, S. B. J. Chem. Phys. 1997, 106, 8940.

(40) Keith, J. A.; Carter, E. A. J. Chem. Theory Comput. 2012, 8, 3187.

(41) Cramer, C. J.J. Chem. Soc., Perkin Trans. 2 1999, 2273. 